\title{
Mental illness in Saudi Arabia: an overview
}

This article was published in the following Dove Press journal:

Psychology Research and Behavior Management

30 January 2015

Number of times this article has been viewed

\begin{abstract}
Adel F Almutairi
Population Health Research Section, King Abdullah International Medical Research Center (KAIMRC), Riyadh, Kingdom of Saudi Arabia; King Saud Bin Abdulaziz University for Health Sciences, Riyadh, Kingdom of Saudi Arabia
\end{abstract}

Correspondence:Adel F Almutairi Population Health Research Section, King Abdullah International Medical Research Center, PO Box 22490, Riyadh II426, Kingdom of Saudi Arabia Email:adel.f.m@hotmail.com

\section{Dear editor}

While I was reading on this topic, I came across an online article attributed to a Saudi psychologist that contained information about mental illness among the Saudi population. What really struck me right away was the estimate that was given for the number of mentally ill people in the country. It was claimed that about half of the Saudi population is suffering from mental illness. ${ }^{1}$ This made me wonder on what grounds the psychologist was basing the claim and how she came up with this scary statistic. If the figure was based on an empirical study, what was the sample size and how robust was the research? Unfortunately, no details were given to answer these questions. Nevertheless, such an alarming figure was the main impetus and driving force for me to write this article and provide readers with an overview of the magnitude of mental illness in the world, and more specifically, in the kingdom of Saudi Arabia, based on recent literature. This article also provides perspectives of scientists working at King Abdullah International Medical Research Center, on how we intend to tackle this issue.

Mental illness is a serious medical condition that affects an individual's thoughts, feelings, mood, and behavior. ${ }^{2}$ There are a wide range of conditions associated with mental illness, such as depression, schizophrenia, bipolar disorder, obsessive compulsive disorder, panic disorder, posttraumatic stress disorder, personality disorder, eating disorders, and addictive behaviors. ${ }^{2,3}$ These kinds of illnesses can affect people of all ages and with different ethnicities, cultures, religions, and incomes. It is noteworthy that not every mental health concern is labeled a mental illness; some people experience transient mental health conditions from time to time. However, these conditions come to be considered mental illnesses if the signs and symptoms persist and disrupt one's ability to function and to relate to others.

The World Health Organization (WHO) recently estimated that one in four peopleabout $25 \%$ of the world population - suffer from mental illness both in the developed and developing worlds. ${ }^{4,5}$ In major industrialized areas like the US, Canada, and Western Europe, mental illness accounts for almost $25 \%$ of all disabilities. It is also considered by the WHO to be the leading cause of disability across the world. ${ }^{4-6}$ Consequently, high financial costs are associated with mental illness due to the loss of productivity that results, as well as the mortality cost. ${ }^{7}$ For example, in the US, it is estimated that the annual indirect cost of mental illness is about $\$ 193.2$ billion. ${ }^{8}$ The global cost is 
estimated at almost $\$ 2.5$ trillion and is expected to rise to $\$ 6$ trillion by $2030 .^{6}$

An overview of the literature in relation to mental illness in Saudi Arabia indicates the lack of an accurate estimate for the prevalence of such problems among the Saudi population. However, a few studies have been conducted in relation to specific mental disorders or particular populations and age groups. ${ }^{9-14}$ For example, a study conducted by Al-Sughayr and Ferwana ${ }^{15}$ measured the prevalence of mental illness among high school students selected from four sites $(\mathrm{N}=354)$ and indicated that the rate of mental illness among the study population was $48 \%$. It was found to be more prevalent among females (51\%) than males (41\%). This study was limited, however, by a relatively small sample size and the used measures. Regardless of individual initiatives to document mental illness in Saudi Arabia, the field of study is still under development. Generally speaking, mental illness is becoming a global concern, and the number of sufferers is reaching crisis level. For this reason, this problem requires proper intervention and management.

For those of us who are researchers, psychologists, health educators, and psychiatrists in Saudi Arabia, we form a part of the international community and need to work collectively to manage the increasing risk of mental illness in the country and beyond. Public educational programs need to be designed to enhance public awareness of mental illnesses, their various potential causes (biological, genetic, and environmental), the preventable consequences, the different treatment regimens available, and the importance of seeking help. Such measures will lead consequently to early detection and proper treatment. These programs should target people in schools, community centers, workplaces, prisons, and so forth. Scientists working at King Abdullah International Medical Research Center, need to identify and investigate the knowledge gaps within mental illness literature in Saudi Arabia and contribute scientifically to knowledge with recommendations for practice. Areas such as women's mental illness, disparities in health services, sociocultural barriers to seeking help, and stigmatization are important for future research. We aim to influence policies related to mental health services and to produce new strategies and methodologies for improving the mental well-being of the Saudi population.

I conclude by stressing the importance of achieving support from both the Government and private agencies in seeking to implement potential initiatives and thus achieving the goal of managing the burden of mental illness, preventing its potential consequences, both on an individual and a national level. Continuous professional development for psychiatric nurses, social workers, psychologists, and other psychiatric staff is important in order to improve the skills and knowledge of health care professionals, using the latest evidence and research.

\section{Disclosure}

The author reports no conflicts of interest in this work.

\section{References}

1. Riyadh-Connect. Half of Saudi Arabia's population is mentally ill says Saudi pyschologist. Riyadh: Riyadh Connect; 2014. Available from: $\mathrm{http}$ ://riyadhconnect.com/half-of-saudi-arabias-population-is-mentallyill/. Accessed December 14, 2014.

2. Duckworth K. Mental Illness: What you Need to Know. Arlington VA: National Alliance on Mental Illness; 2013.

3. Doran CM. Prescribing Mental Health Medication: The Practitioner's Guide. New York, NY: Routledge; 2005.

4. World Health Organization. WHO Mental Health Gap Action Programme (mhGAP). Geneva: World Health Organization; 2013.

5. World Health Organization. Mental Health Atlas 2011. Geneva: World Health Organization; 2011:82.

6. National Alliance on Mental Illness. Mental Health 2013: An Important Public Health Issue; 2013. Available from: http://www.namigc.org/ wp-content/uploads/2013/01/MentalIllnessFactSheet-July-2013.pdf. Accessed December 14, 2014.

7. Kemp D. Mental Health in America. Santa Barbara, CA: ABC-CLIO; 2007.

8. Duckworth K. Mental Illness Facts and Numbers. Arlington, VA: National Alliance on Mental Illness; 2013.

9. Becker S, Al Zaid K, Al Faris E. Screening for somatization and depression in Saudi Arabia: a validation study of the PHQ in primary care. Int J Psychiatry Med. 2002;32(3):271-283.

10. Al-Khathami AD, Ogbeide DO. Prevalence of mental illness among Saudi adult primary-care patients in Central Saudi Arabia. Saudi Med J. 2002;23(6):721-724.

11. Bassiony M. Substance use disorders in Saudi Arabia: review article. J Subst Use. 2013;18(6):450-466.

12. Al-Gelban KS. Depression, anxiety and stress among Saudi adolescent school boys. J R Soc Promot Health. 2007;127(1):33-37.

13. AbuMadini MS, Rahim SI, Al-Zahrani MA, Al-Johi AO. Two decades of treatment seeking for substance use disorders in Saudi Arabia: trends and patterns in a rehabilitation facility in Dammam. Drug Alcohol Depend. 2008;97:231-236.

14. Becker SM. Detection of somatization and depression in primary care in Saudi Arabia. Soc Psychiatry Psychiatr Epidemiol. 2004;39:962-966.

15. Al-Sughayr AM, Ferwana MS. Prevalence of mental disorders among high school students in National Guard Housing, Riyadh, Saudi Arabia. J Fam Community Med. 2012;19(1):47-51. 
Psychology Research and Behavior Management

Dovepress

\section{Publish your work in this journal}

Psychology Research and Behavior Management is an international, peerreviewed, open access journal focusing on the science of psychology and its application in behavior management to develop improved outcomes in the clinical, educational, sports and business arenas. Specific topics covered include: Neuroscience, memory \& decision making; Behavior modification \& management; Clinical applications; Business \& sports performance management; Social and developmental studies; Animal studies. The manuscript management system is completely online and includes a quick and fair peer-review system. Visit http://www.dovepress. com/testimonials.php to read real quotes from published authors.

Submit your manuscript here: http://www.dovepress.com/psychology-research-and-behavior-management-journal 